\title{
Mycobacterium bovis, but also $M$. africanum present in raw milk of pastoral cattle in north-central Nigeria
}

\author{
Simeon I. B. Cadmus • Mohammed K. Yakubu • \\ Abdullahi A. Magaji • Akinbowale O. Jenkins • \\ Dick van Soolingen
}

Accepted: 12 February 2010

(C) Springer Science+Business Media B.V. 2010

\begin{abstract}
Using deletion typing technique, five mycobacteria isolated from unpasteurised milk samples from cows in north-central Nigeria were characterized as Mycobacterium bovis $(n=4)$ and M. africanum $(n=1)$. This report emphasizes that transmission between the animal and human reservoir is a serious threat in Nigeria.
\end{abstract}

Keywords Mycobacterium bovis · Pasteurization ·

Zoonosis $\cdot$ Milk $\cdot$ Nigeria

\begin{tabular}{|c|c|}
\hline \multicolumn{2}{|l|}{ Abbreviations } \\
\hline MTC & $\begin{array}{l}\text { Mycobacterium tuberculosis } \\
\text { complex }\end{array}$ \\
\hline $\mathrm{NALC}-\mathrm{NaOH}$ & $\begin{array}{l}\text { N-acetyl-L-cysteine Sodium } \\
\text { hydroxide }\end{array}$ \\
\hline NPC & National Population Commission \\
\hline RD & Regions of difference \\
\hline TB & Tuberculosis \\
\hline
\end{tabular}

S. I. B. Cadmus $(\bowtie)$

Department of Veterinary Public Health and Preventive Medicine, University of Ibadan,

P.O. Box 21452, U.I. Post Office,

Ibadan, Nigeria

e-mail: sibcadmus@yahoo.com

M. K. Yakubu • A. A. Magaji

Department of Veterinary Public Health and Animal Production,

Faculty of Veterinary Medicine, Usmanu Danfodiyo University,

P.M.B. 2346 Sokoto, Nigeria

A. O. Jenkins

Department of Veterinary Tropical Disease,

Faculty of Veterinary Sciences, University of Pretoria,

Pretoria, South Africa

D. van Soolingen

National Institute for Public Health and the Environment (RIVM),

3720 BA Bilthoven, The Netherlands

\section{Introduction}

In most African countries, consumption of unpasteurized milk is a regular practice (Ayele et al. 2004) leading to considerable risk of zoonotic infection with Mycobacterium bovis and other mycobacteria. M. bovis has been isolated earlier from unpasteurized milk and lesions of slaughtered cattle in Nigeria, as well as from patients with pulmonary and extrapulmonary tuberculosis (TB; Cadmus et al. 2006).

Most cow milk consumed in north-central Nigeria is from livestock owners who are unaware of the public health risks associated with bovine tuberculosis (BTB). To estimate the risk of zoonotic transmission of mycobacteria, we screened raw milk of pastoral cattle from north-central Nigeria for these bacteria and identified them using a molecular method.

\section{Materials and methods}

Study area The work was conducted at the South Agricultural Zone of Niger State, north-central Nigeria.

Sample collection About $20 \mathrm{ml}$ of milk was drawn from the disinfected udder of selected cows into sterile universal bottles from each of the 400 out of a total of 4,023 cattle representing $10 \%$ of the 416 identified herds. Samples were selected using the systematic sampling technique while the herds were identified by physical randomization technique (Cameroon, 2003).

Isolation of mycobacteria This was done as described by Cadmus and Adesokan (2007), using Middlebrook 7H11 slopes and incubating at $37^{\circ} \mathrm{C}$ for 12 weeks. 
Table 1 Result of deletion typing

\begin{tabular}{lll}
\hline $\begin{array}{l}\text { Regions of } \\
\text { differences (RD) }\end{array}$ & M. bovis & M. africanum \\
\hline RD1 & Present & Present \\
RD4 & Absent & Present \\
RD9 & Absent & Absent \\
RD12 & Absent & Present \\
\hline
\end{tabular}

Deletion typing The RD9 deletion was used to distinguish Mycobacterium tuberculosis from other members of the $M$. tuberculosis complex (MTC; Warren et al. 2006). Isolates with a deletion in this region were further investigated with primers specific for RD4. This reaction distinguishes between M. bovis, M. caprae, and other MTC.

\section{Results and discussion}

Of the 400 milk samples, five (1.25\%) were positive by culture and further molecular analysis identified four $M$. bovis and one M. africanum (Table 1). Herd and individual animal prevalence amounted to $10 \%(4 / 40)$ and $1.25 \%(5 /$ 400), respectively.

We report the first molecular characterisation of M. bovis and $M$. africanum from unpasteurised milk of pastoral cattle in north-central Nigeria. This may be an important finding considering that although people in this region suffer from tuberculosis, there are no documented literature to show a reliable identification of Mycobacterium humans are exposed to.

The findings indicate that there is high herd prevalence of BTB in this region, leading to serious public health implications. Therefore, since BTB is endemic in Nigeria, it becomes imperative to carry out surveillance programs to forestall zoonotic spread going by the reports of Hlavsa et al. (2008) and Ayele et al. (2004) that approximately 1.4\% of human tuberculosis cases in the developed countries and $3.1 \%$ in the developing countries, respectively, could be attributed to M. bovis.

It is noticeable that not only $M$. bovis, but also $M$. africanum was isolated from milk of cows. It is known that the latter species is more related to $M$. bovis than $M$. tuberculosis, but it remains unclear whether it is also transmitted among cows, or whether this is an accidental transmission of $M$. africanum from humans to cows as reported several times for $M$. tuberculosis. However, the presence of $M$. africanum in milk hints at a disseminated infection in the cow, and this is to our knowledge, not reported for this bacterium.

The limitations of this study (i.e., screening of limited numbers of animals and lack of collection of specimens from tuberculosis patients in adjoining hospitals to link them directly with the animals or consumption of milk products as recently done by Byarugaba et al. (2009) in Uganda) notwithstanding, the habit of pooling milk in this region poses great danger to people who consume them raw as fresh or fermented product.

In conclusion, there is the need for pasteurization of milk from pastoral herds in Nigeria to prevent zoonotic transmission of tuberculosis.

Acknowledgments The authors are immensely grateful to Dr. Kehinde Adesokan and Dr. Charity Agada for technical assistance. We are also grateful to Dr Femi Faleke for his support at the inception of the study.

\section{References}

Ayele, W.Y., Neill, S.D., Zinsstag, J., Weiss, M.G. and Pavlik, I., 2004. Bovine tuberculosis: an old disease but a new threat to Africa, International Journal of Tuberculosis and Lung Diseases, 8, 924-937

Byarugaba, F., Etter, E. M. C., Godreuil, S., Grimaud, P., 2009. Pulmonary tuberculosis and Mycobacterium bovis, Uganda. Emerging Infectious Diseases. doi:10.3201/eid1501.080487

Cadmus, S.I.B., Palmer, S., Okker, M., Dale, J., Gover, K., Smith, N., Jahans, K., Hewinson, R.G. and Gordon, S.V., 2006. Molecular analysis of human and bovine tubercle bacilli from a local setting in Nigeria, Journal of Clinical Microbiology, 44, 29-34

Cadmus, S.I.B. and Adesokan, H.K., 2007. Phenotypic Characterization and spoligotype profiles of Mycobacterium bovis isolated from unpasteurized cows' milk in Ibadan, Nigeria, Tropical Veterinarian, 25, 65-72

Cameroon, A., 2003. Survey tool for livestock diseases, a practical manual and software package for surveillance in developing countries. Australian Centre for International Agricultural Research (ACIAR) Monograph 54

Hlavsa, M.C., Moonan, P.K., Cowan, L.S., Navin, T.R., Kammerer, J.S., Morlock, G.P., Crawford, J.T., and LoBue, P.A., 2008. Human tuberculosis due to Mycobacterium bovis in the United States, 1995-2005, Clinical Infectious Diseases, 47, 168-175.

Leite, C.Q., Anno, I.S., Leite, S.R., Roxo, E., Morlock, G.P. and Cooksey, R.C., 2003. Isolation and identification of Mycobacterium from livestock specimens and milk obtained in Brazil, Memorias do Isntituto Oswaldo Cruz, 98, 319-23

Ofukwu, R.A., Oboegbulem, S.I. and Akwuobu, C.A., 2008. Zoonotic Mycobacterium species in fresh cow milk and fresh skimmed, unpasteurised market milk (nono) in Makurdi, Nigeria: implications for public health, Journal of Animal and Plant Science, 1, 21-25

Warren, R.M., Gey van Pittius, N.C., Barnard, M., Hesseling, A., Engelke, E., de Kock, M., Gutierrez, M.C., Chege, G.K., Victor, T.C., Hoal, E.G. and van Helden, P.D., 2006. Differentiation of Mycobacterium tuberculosis complex by PCR amplification of genomic regions of difference, International Journal of Tuberculosis and Lung Diseases, 10, 818-822 